Iva Seto

Victoria University of Wellington, Wellington, New Zealand

David Johnstone

Victoria University of Wellington, Wellington, New Zealand

Jennifer Campbell-Meier

Victoria University of Wellington, Wellington, New Zealand

\title{
Expert Advisory Groups: Exploring the Sensemaking Process During a Public Health Crisis Response (Poster)
}

\begin{abstract}
:
In a public health crisis, key decision makers may seek support from expert advisors. Experts must process information to provide advice as quickly as possible, yet this must be balanced with ensuring the information is credible, reliable, and relevant. This research will explore how experts engage in sensemaking during the period of crisis response.
\end{abstract}

\section{Résumé:}

\section{Introduction}

During a public health crisis, the response is managed by key decision makers (KDMs) often in an Emergency Operations Centre (EOC). An Expert Advisory Group (EAG) supports KDMs regarding the scientific/medical aspect of the disease, and are not necessarily in the EOC. The EAG is comprised of specialists such as epidemiologists, public health officers, virologists, nurses, and physicians. KDMs rely on trustworthy advice from the EAG as quickly as possible in order to manage the crisis (Alison et al., 2015). The challenge for all involved is to proceed under conditions of information overload and burnout (Bawden \& Robinson, 2009). Additionally, members of the EAG need to manage the tension between the volume of workload, and providing optimal advice based on best evidence and their collective expertise, as quickly as possible (Lipsitch et al., 2011).

\section{Sensemaking during a public health crisis}

Sensemaking is a meaning creation process; this research will utilise the sensemaking perspective from a socio-constructivist approach, focusing on the meaning creation process between people rather than within individuals (Maitlis \& Christianson, 2014; Weick, 1995). Sensemaking is a process that begins with a trigger, such as an unexpected occurrence that leads to a gap between what was expected and what was experienced. The process continues to bracketing (characterising the gap), interpretation (meaning creation), assessing plausibility of the interpretation, and arriving to a created meaning that fills the gap (Weick, 1995).

Research on crisis sensemaking has mostly focused on acute crises such as wildfires (Weick, 1993), industrial explosions (Weick, 1988), or pursuit of a suspected terrorist (Colville, Pye 
\& Carter, 2013). Long duration (several months or longer) organisational sensemaking research has been in non-crisis settings (Maitlis, 2005).

A public health emergency (such as a pandemic) requires a completely different type of response than a natural disaster, such as an earthquake or tsunami, which is usually in active response for up to 72 hours (Ruback, Wells, \& Maguire, 2013). For a public health crisis, key decision makers and their advisors must sort and analyse large volumes of information through intense time-pressure in order to save lives and contain the disease, and this may extend for several months, or even longer. Unlike natural disasters, by the time a public health emergency is declared, the virus may have spread and created a reservoir in the population. Officials must often wait and monitor the population to see who may have symptoms of the disease, which is dependent on the incubation period of the virus.

Over the course of a long duration crisis event, organisations may adapt and change by learning through the sensemaking process. Organisational research has mainly focused on learning from rare events, rather than learning through rare events (Christianson et al., 2009; Lampel, Shamsie, \& Shapira, 2009). Examining a public health crisis offers the opportunity to explore the experience of sensemaking and learning through a long duration crisis event.

\section{Proposed research}

The sensemaking perspective will be the lens to explore how EAGs collectively engage in the process of providing advice to KDMs; attention will be paid to the extent this process changes over the course of the crisis. Furthermore, the role of information in the process of providing advice will be examined.

This research will focus on the Severe Acute Respiratory Syndrome (SARS) crisis in Canada as a case study. Three phases of data collection are planned:

- Phase 1 is a review and analysis of newspaper articles (The Globe and Mail, and Toronto Star) relevant to the EAG during the SARS crisis (March to July, 2003), as well as the SARS Commission (Campbell, 2006), a public inquiry report.

- Phase 2 is an exploration of the materials housed at the Archives of Ontario. Specifically, documents (and/or artifacts) used and produced by the EAG will be sought for analysis.

- Phase 3 will be in-depth research interviews with participants recruited from the EAG members and stakeholders.

This study aims to contribute an integrated conceptual framework on organisational sensemaking and learning, as well as provide initial findings that may aid in the improvement of public health crisis response planning and/or policy.

\section{Reference list:}

Alison, L., Power, N., van den Heuvel, C., Humann, M., Palasinksi, M., \& Crego, J. (2015). Decision inertia: Deciding between least worst outcomes in emergency responses to disasters. Journal of Occupational and Organizational Psychology, 88(2), 295-321. 
Bawden, D., \& Robinson, L. (2009). The dark side of information: overload, anxiety and other paradoxes and pathologies. Journal of Information Science, 35(2), 180-191.

Campbell, A. (2006). SARS Commission: Spring of Fear. Toronto: Publications Ontario.

Christianson, M. K., Farkas, M. T., Sutcliffe, K. M., \& Weick, K. E. (2009). Learning through rare events: Significant interruptions at the Baltimore \& Ohio Railroad Museum. Organization Science, 20(5), 846-860.

Colville, I., Pye, A., \& Carter, M. (2013). Organizing to counter terrorism: Sensemaking amidst dynamic complexity. Human Relations, 66(9), 1201-1223.

Lampel, J., Shamsie, J., \& Shapira, Z. (2009). Experiencing the improbable: Rare events and organizational learning. Organization Science, 20(5), 835-845.

Lipsitch, M., Finelli, L., Heffernan, R. T., Leung, G. M., Redd, \& for the H1N1 Surveillance Group, S. C. (2011). Improving the evidence base for decision making during a pandemic: the example of 2009 influenza A/H1N1. Biosecurity and bioterrorism: biodefense strategy, practice, and science, 9(2), 89-115

Maitlis, S. (2005). The Social Processes of Organizational Sensemaking. Academy of Management Journal, 48(1), 21-49.

Maitlis, S., \& Christianson, M. (2014). Sensemaking in Organizations: Taking Stock and Moving Forward. The Academy of Management Annals, 8(1), 57-125.

Ruback, J., Wells, A. S., \& Maguire, B. J. (2013). Methods of Planning and Response Coordination. In R. Bissell (Ed.), Preparedness and Response for Catastrophic Disasters. Boca Raton, FL: Taylor \& Francis.

Weick, K. E. (1988). Enacted sensemaking in crisis situations. Journal of Management Studies, 25(4), 305-317.

Weick, K. E. (1993). The Collapse of Sensemaking in Organizations: The Mann Gulch Disaster. Administrative Science Quarterly, 38(4), 628-652.

Weick, K. E. (1995). Sensemaking in Organizations: Sage. 